\title{
TECHNOLOGY FOR RESTORATION AND REPAIR OF AIRCRAFT ENGINE PARTS
}

\author{
Serhii NYZHNYK (D) ${ }^{1}$, Ihor ZORIK (DD ${ }^{1}$, Kostiantyn DANKO (D) ${ }^{1 *}$, Justas NUGARAS (D) ${ }^{2}$ \\ ${ }^{1}$ Faculty of Aircraft Engines Manufacturing Technology, National Aerospace University \\ "Kharkiv Aviation Institute", Kharkiv, Ukraine \\ ${ }^{2}$ Antanas Gustaitis Aviation Institute, Vilnius Gediminas Technical University, Vilnius, Lithuania
}

Received 12 April 2021; accepted 18 August 2021

\begin{abstract}
Problems of increasing the service life of compressor blades of aircraft gas turbine engines using detonation spraying technology are considered. The simulation of the parameters of the velocity and temperature of the particles of the sprayed material in the barrel of the detonation unit and in the flooded space to the substrate was carried out, followed by the choice of the optimal technological parameters of the spraying process. The control system of the detonation unit has been modernized. An experiment was carried out on the deposition of the $\mathrm{Al}_{2} \mathrm{O}_{3}$ coatings on the samples of a substrate made of titanium alloy VT3-1. Based on the results of the experiment, technological recommendations were developed concerning both the parameters of the spraying process and the parameters of the preparation of the substrate surface before spraying. The equipment for brazing the blades of the guide vanes is described and a device for spraying coatings on the end surfaces of the compressor blades is proposed. Thus, a complex technology has been developed for restoring the end surfaces of titanium alloy compressor blades by deposition of $\mathrm{Al}_{2} \mathrm{O}_{3}$ coatings.
\end{abstract}

Keywords: coating, blade, energy, deformation, adhesive strength, cohesive strength, end face, technologies.

\section{Introduction}

Modern aircraft engines are a scientific and high-tech product, which has no analogs in terms of stress level and thermal condition of parts among other engineering products. The features of aircraft engine construction are the following: medium-sized dimensions, form complexity, thinness, high accuracy of manufacturing parts, the use of a large number of different materials and processing types, mandatory development of technical documentation, and mandatory manufacturing quality control, and frequent change of production objects.

In analyzing the impact on the operating characteristics of various parts, it should be noted that the engine's service life and reliability are determined by the endurance of the blades, discs, shafts, subjected to alternating and cyclic loads (Boyce, 2012). Among the above-mentioned parts, the most numerous, complex in configuration and variety of used materials are compressor and turbine blades, their manufacturing process presupposes the use of all types of metalworking, followed by finishing and strengthening (IDC Technologies, 2013). It should be noted the peculiarities of engines' operating conditions installed on helicop- ters. The compressor blades of these engines are subject to erosion and the speed depends on the dispersion and mineralogical composition of soil dust at the take-off and landing runways.

Concerning the cost of engine blades' repairing, it is possible to use neighboring blades, which are also subject to erosion on the engine being repaired, but the geometric parameters do not exceed the erosion limits. It is important to develop equipment for unsoldering the blades to be repaired from the half-rings of the guide devices and for ensuring the proper geometry of the gas-dynamic path during installation after restoration.

Thus, research aimed at the modernization and development of equipment, recommendations for the implementation of innovative technological processes for repair, restoration geometry, since the quality and durability of aircraft engines parts are relevant.

\section{Literature review}

Intensification of operating processes, increase in intensity and scales of aviation equipment application, increase in constructive complexity, and cost of aircraft engines

${ }^{*}$ Corresponding author. E-mail: k.danko@khai.edu

Copyright $\odot 2021$ The Author(s). Published by Vilnius Gediminas Technical University

This is an Open Access article distributed under the terms of the Creative Commons Attribution License (https://creativecommons.org/licenses/by/4.0/), which permits unrestricted use, distribution, and reproduction in any medium, provided the original author and source are credited. 
demands high reliability and durability of their details and components (Volkov, 2012).

Compressor blades are the largest scale parts, and also directly affect the stability of the engine's operation, as a product that determines the increased attention at all stages of the life cycle, and its quality (Jansohn, 2013). It is identified the most characteristic types of runouts occur during the operational process (Ciafone, 2011).

The analysis conducted with the perspective of revealing an effective restoration technique determined that one of the most rational ways to improve the performance properties can be achieved by technological methods of three dimensional (Farokhi, 2014) or surface strengthening (Kato et al., 2014). It is necessary to apply the optimum methods and types of repair and restoration providing the reliability indicators (Reitz et al., 2016), to choose materials with sufficient specific durability (Sharma et al., 2017).

Modern methods of thermal spraying (TS) of coatings make it possible to obtain different types of coatings with high characteristics of wear resistance, heat resistance (Alqallaf et al., 2020), corrosion resistance (Grilli et al., 2021), but one of the main components of the coating performance characteristics is the adhesive strength (Dolmatov \& Bilchuk, 2019).

Repair and restoration of worn parts also require the correct determination of the technical condition of the part, the cause of damage, to make the right decision to eliminate the identified defects and failures, as well as to provide high-quality repair work (Dolmatov \& Bilchuk, 2018). Operational characteristics of details and components of aircraft engines essentially depend on characteristics of surface quality and a near-surface layer. Modern methods of improving the operational characteristics of parts and components of aircraft engines are based on the surface layer improving quality.

\section{Two-phase flow simulation}

Modern methods of thermal spraying of coatings make it possible to obtain different types of coatings with high characteristics of wear resistance, heat resistance, corrosion resistance, but one of the main components of the operational characteristics of the coating is the adhesive strength.

The following model is chosen as the basic: a barrel of length $l$ and diameter $d$, partially filled with a gas mixture capable of detonating at initial pressures $\mathrm{P} 0$, density $\rho_{0}$, and temperature $T_{e}$. Part of the barrel is filled with inert gas. The motion of the medium is described in coordinates, the beginning is connected with the closed end of the barrel, and X-axis is directed toward the open end of the barrel. At some distance from the closed end of the barrel between the sections, $\mathrm{X} 1$ and $\mathrm{X} 2$ are suspended particles of powder with a bulk concentration $\alpha_{2}$. The detonation wave is formed and propagates into the mixture as a result of the explosion initiation near the closed end of the barrel (Dolmatov et al., 2015). Upon reaching the contact limit, the detonation wave turns into a shock wave moving through the inert gas (Dolmatov et al., 2014).

In the propagation of the detonation wave and the subsequent flow out of detonation products from the barrel, there is a force and thermal interaction of the powder particles with the detonation wave and the detonation products. It is necessary to determine the parameters of detonation products and powder particles depending on time. The analysis of two-phase flows is carried out under the following assumptions: the pressure is created by gas only, the influence of particles is neglected; solid particles that are spheres of the same radius, equally-spaced between the sections X1 and X2 in the barrel and interact with each other and the barrel's walls, the particles are inert and do not interact with the products of detonation; there is no mass transfer between gas and powder; the volume occupied by the particles can be neglected; due to the high thermal conductivity of the particles' material, their temperature in the entire volume is constant; gravitational and electric forces can be neglected (Davidson, 2015).

The studies' analysis of two-phase gas flows with particles (Anderson, 2012; Wilcox, 2006) determines that in the last few decades this issue has periodically aroused constant interest (Lomax et al., 1999). It should be noted that most calculations of carrier gas flows are based on the Navier-Stokes equations (White, 2011), averaged by the Reynolds RANS (Reynolds Averaged Navier-Stokes system), with one or another model of turbulence (Versteeg \& Malalasekra, 2007).

$$
\left\{\begin{array}{l}
\frac{\partial \rho}{\partial t}+\frac{\partial}{\partial x_{k}}\left(\rho u_{k}\right)=0, \\
\frac{\partial\left(\rho u_{i}\right)}{\partial t}+\frac{\partial}{\partial x_{k}}\left(\rho_{i} u_{k}-\tau_{i k}\right)+\frac{\partial P}{\partial x_{i}}=S_{i}, \\
\frac{\partial(\rho E)}{\partial t}+\frac{\partial}{\partial x_{k}}\left((\rho E+P) u_{k}+q_{k}-\tau_{i k} u_{k}\right)=S_{k} u_{k}+Q_{H},
\end{array}\right.
$$

where $u_{i}$ is gas velocity vector components; $\rho, P$ are the gas density and pressure; $S_{i}$ - external bulk forces; $E$ is the total energy of a gas unit mass; $Q_{H}$ - heat released in a gas unit volume; $\tau_{i k}$ - tensor of viscous shear stresses; $q_{i}$ is the heat flow.

Applying the advantages of $\mathrm{k}-\varepsilon$ models in describing flows and $\mathrm{k}-\omega$ models in describing wall functions, it was implemented in a two-layer Menter model (Menter, 1993), which provides a smooth transition from the $\mathrm{k}-\omega$ model in the wall area to the k- $\varepsilon$ model far from the wall (Zorik, 2020).

The basic two-layer Menter model can be presented as follows:

$$
\begin{aligned}
& \rho \frac{\partial k}{\partial t}+\rho \bar{u}_{j} \frac{\partial k}{\partial x_{j}}=\tau_{i j} \frac{\partial u_{i}}{\partial x j}-\rho \beta \cdot k \omega+\frac{\partial}{\partial x_{j}}\left[\left(\mu+\sigma_{k} \mu_{t}\right) \frac{\partial k}{\partial x_{j}}\right], \\
& \rho \frac{\partial \omega}{\partial t}+\rho \bar{u}_{j} \frac{\partial \omega}{\partial x_{j}}=\gamma \frac{\omega}{k} \tau_{i j} \frac{\partial \bar{u}_{i}}{\partial x_{j}}-\beta \rho \omega^{2}+ \\
& \frac{\partial}{\partial x_{j}}\left[\left(\mu+\sigma_{\omega} \mu_{t}\right) \frac{\partial \omega}{\partial x_{j}}\right]+2\left(1-F_{1}\right) \rho \sigma_{\omega^{2}} \frac{1}{\omega} \frac{\partial k}{\partial x_{j}} \frac{\partial \omega}{\partial x_{j}} .
\end{aligned}
$$




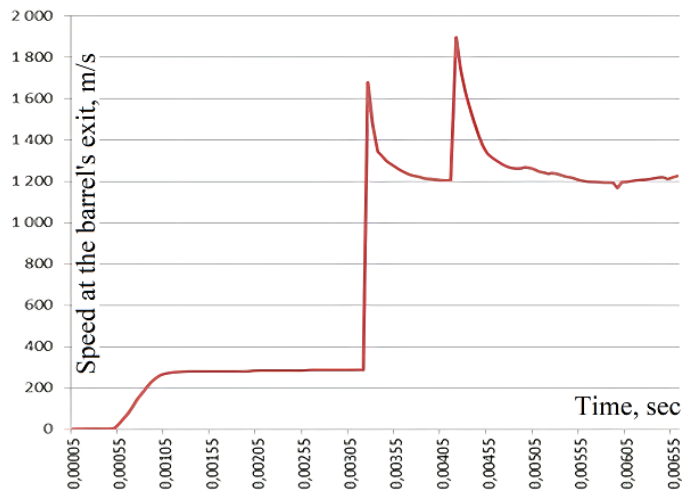

a.

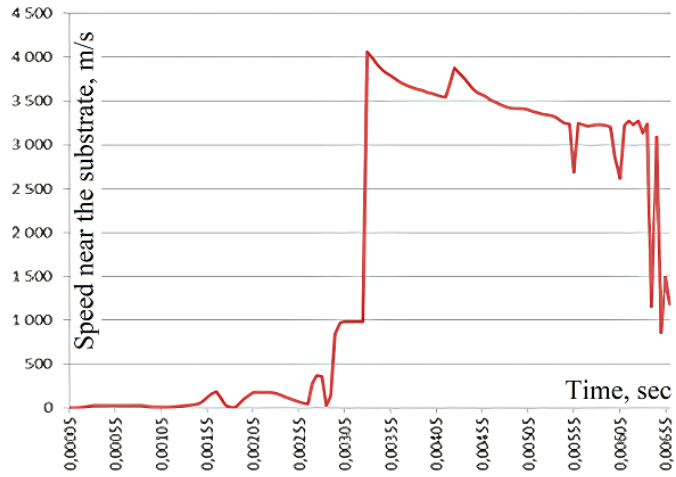

b.

Figure 1. Carrier gas speed paramenters: $\mathrm{a}$ - at the barrel's exit of the D-gun; b - near the substrate

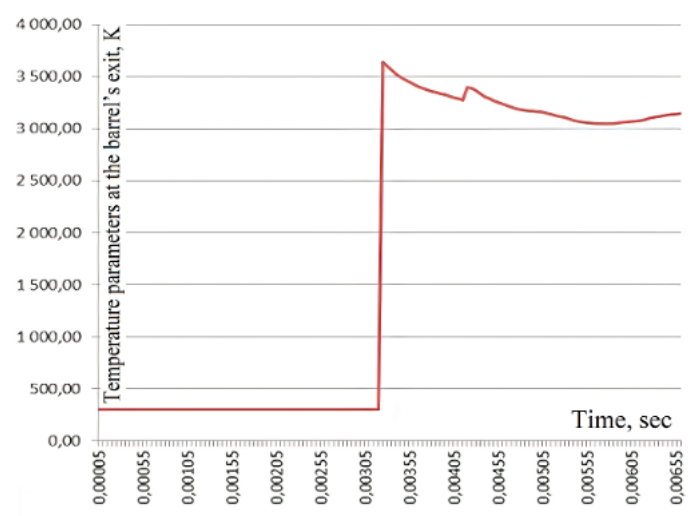

a.

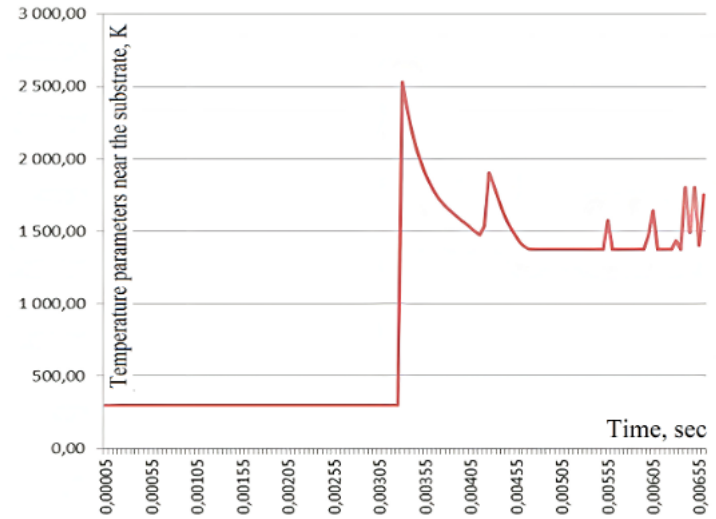

b.

Figure 2. Carrier gas temperature parameters: $\mathrm{a}$ - at the barrel's exit of the D-gun; $\mathrm{b}$ - near the substrate

Calculations were performed for MAF mixtures of (methylacetylene-allene fraction (MAF)) and oxygen in the ratio from equimolar to stoichiometric. The calculation results of the gas-dynamic parameter distribution are shown in Figures 1 and 2.

The concept of homogeneous multiphase Euler modeling was used to model the interaction of powder particles with the flow - a model of liquid volume (VOF), which presupposes that two liquids (or phases) do not penetrate into each other in any given area of the control volume on the particle's volumes of local phases (Karypis \& Kumar, 1997).

\section{Experimental results}

\subsection{Optimization of process parameters}

The device was upgraded to optimize the manufacturing parameters of the coating process. The manufacturability of the device is provided by the modularity, as well as the possibility of adjustment and control, which ensured the compactness of the device compared to the previous version.

It is advisable to use a multi-seat device (Figure 3 ) to deposit the coating on the end face of the blades.

In choosing the optimal parameters for coating are focused primarily on their functional purpose, but one of the main parameters of optimization is the adhesion strength for coatings operating under significant mechanical loads.

Additional parameters that directly affect the adhesive and cohesive strength are also significantly affected by the spraying distance, the fraction of the applied material, and the surface preparation for spraying, in particular the surface roughness.

The experiments were additionally performed (see Table 1) to confirm that the determining factor is the adhesion strength of the coatings, which allow comparing the adhesion strength and the strength of the coating on similar technological modes.

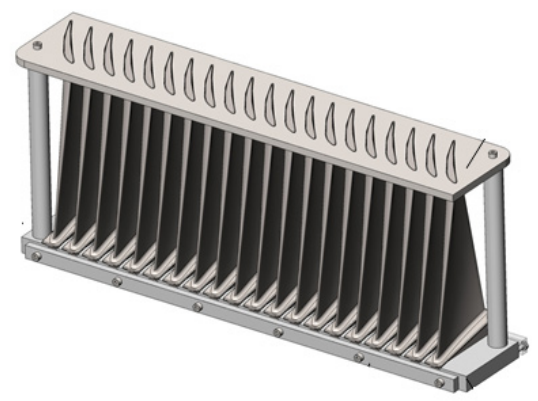

Figure 3. General view of the multi-seat device 
Table 1. $\mathrm{Al}_{2} \mathrm{O}_{3}$ coatings' strength

\begin{tabular}{|c|c|c|c|c|c|c|c|c|}
\hline \multirow{2}{*}{ Sample } & \multirow{2}{*}{$\begin{array}{c}\text { Fraction, } \\
\mu \mathrm{m}\end{array}$} & \multirow{2}{*}{$\begin{array}{l}\text { Roughness, } \\
\mu \mathrm{m}\end{array}$} & \multicolumn{2}{|c|}{$\begin{array}{l}\text { Sample diameter, } \\
\mathrm{mm}\end{array}$} & \multirow{2}{*}{$\begin{array}{c}\text { Coating } \\
\text { thickness, } \\
\Delta, \mathrm{mm}\end{array}$} & \multirow{2}{*}{$\begin{array}{l}\text { Coating } \\
\text { area, } \mathrm{mm}^{2}\end{array}$} & \multirow{2}{*}{ Load, N } & \multirow{2}{*}{$\begin{array}{c}\text { Coating } \\
\text { strength, MPa }\end{array}$} \\
\hline & & & Before coating & After coating & & & & \\
\hline 1 & 10 & 87.5 & 25.46 & 25.84 & 0.38 & 15.31 & 1452.8 & 94.889 \\
\hline 2 & 45 & 87.5 & 25.43 & 25.89 & 0.46 & 18.54 & 2363.813 & 127.491 \\
\hline 3 & 80 & 87.5 & 25.54 & 25.9 & 0.36 & 14.54 & 1474.587 & 101.386 \\
\hline
\end{tabular}

The rational regimes for $\mathrm{Al}_{2} \mathrm{O}_{3}$ material are determined based on mathematical modeling of the two-phase flow in the barrel of the detonation unit at the flow-out into the flooded space and interaction with the substrate, the parameters of velocity and temperature are calculated.

It was evaluated the influence of the spraying distance, the particles size distribution of powder materials, and the state of the substrate surface on the bond strength, it was determined the rational ratios achieve maximum coating and adhesion strengths based on a small factorial experiment.

\subsection{Effect of the new technological process introduction}

The cross-sections were prepared to study the influence of the parameters of alumina ceramic coatings on metal substrates made of VT3-1 alloy on the microstructure of the coating and the boundaries of the section "ceramic coating - metal substrate", as well as to study the mechanical properties of coatings on the samples. Considering the poor polishing ability of $\mathrm{Al}_{2} \mathrm{O}_{3}$, as well as the presence of possible porosity in the powder coatings, the preparation of the section was carried out as follows: the samples were clamped in a metal clamp with plane-parallel sides. Rough grinding of the surface was performed with grinding paper of different grain sizes (Dolmatov et al., 2013), and finishing with the use of polishing pastes such as ASN and AFM with a dispersion that is part of the diamond crumb from 6 to $0.1 \mu \mathrm{m}$.

The analysis of the microstructure, morphology of the coatings, and the transition zone was performed using an electron scanning microscope with a low vacuum chamber and an energy dispersion microanalysis system REM-106. Figure 4 shows the results of studies of $\mathrm{Al}_{2} \mathrm{O}_{3}$ coatings. Quantitative analysis of the porosity of coatings was performed (Figure 5).

The resulting coating is an oxide with a pronounced non-metallic nature. The thickness of the coating is up 140 to $280 \mu \mathrm{m}$. The difference in relief reaches $15 \mu \mathrm{m}$.

The edge between the coating and the matrix metal is relatively developed. The penetration depth of individual sections of alumina reaches $15 \mu \mathrm{m}$ relative to the main edge, which slightly increases the adhesive strength of the coating with the base.

X-ray diffraction analysis was performed on a DRON-3 diffractometer in a monochromatized $\mathrm{K} \alpha-\mathrm{Cu}$ measurement. Diffractograms were taken in the range of angles $2 \Theta=15-60^{\circ}$. Decoding of diffraction patterns was performed using the ASTM file. The results indicate the crystalline structure of the coatings. The phase composition of the coatings on all test samples is identical and represents a mixture of modifications of alumina- $\gamma-\mathrm{Al}_{2} \mathrm{O}_{3}$ and $\alpha-\mathrm{Al}_{2} \mathrm{O}_{3}$.

An axial texture of type $<100>$ normal to the surface of the coating was detected on all coatings. The results of quantitative X-ray analysis and microhardness of the coatings are shown in Table 2.

Microhardness was measured on a PMT-3 microhardness tester ( $P=200 \mathrm{~g}$ ). Carrying out the measurement of microhardness on the surface of the coating is impossible, due to the rather large surface ripple and the possible distortion of the results due to the presence of a "loose
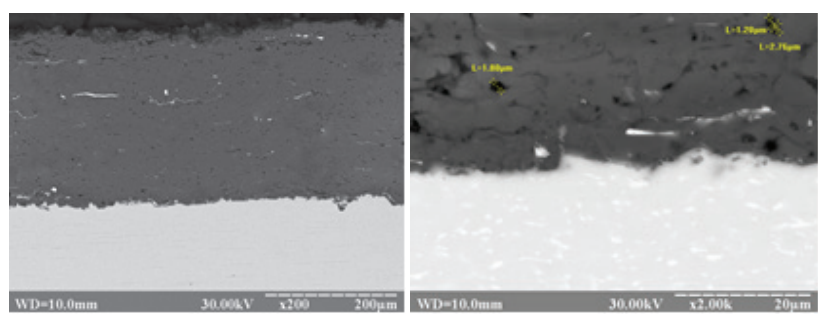

Figure 4. General view of the coating on the samples (cross section) grain-thickness F240
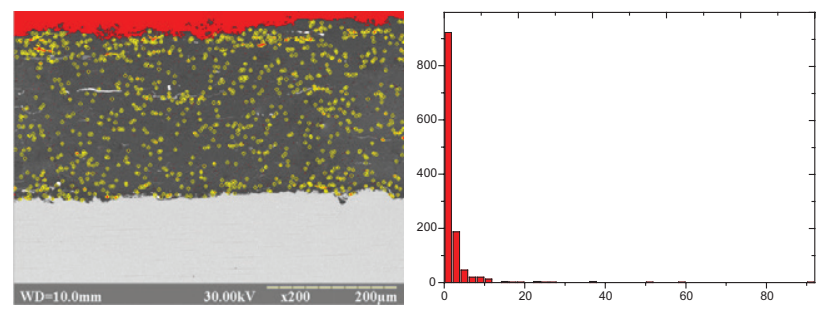

Figure 5. Selection and measurement of pore area in coating, grain-thickness F240

Table 2. $\mathrm{Al}_{2} \mathrm{O}_{3}$ coating microhardness

\begin{tabular}{|c|c|c|c|c|}
\hline $\begin{array}{c}\text { Sample } \\
\text { № }\end{array}$ & $\begin{array}{c}\text { Layer thickness, } \\
\mu \mathrm{m}\end{array}$ & $\alpha-\mathrm{Al}_{2} \mathrm{O}_{3}$ & $\gamma-\mathrm{Al}_{2} \mathrm{O}_{3}$ & $\mathrm{HV}$ \\
\hline \multirow{2}{*}{1} & 350 & 15 & 85 & - \\
\cline { 2 - 5 } & 250 & 17 & 83 & 1400 \\
\hline \multirow{2}{*}{2} & 390 & 19 & 81 & - \\
\cline { 2 - 5 } & 350 & 20 & 80 & 1500 \\
\hline \multirow{2}{*}{3} & 200 & 20 & 80 & - \\
\cline { 2 - 5 } & 150 & 22 & 78 & 1400 \\
\hline
\end{tabular}


layer". Measurements were performed after removing the top layer of coating from 50 to $100 \mu \mathrm{m}$.

It should be noted that the phase composition and microhardness are almost the same for the presented samples, but the size and number of pores in the coating differs significantly, which suggests that the choice of optimal parameters should be approached with special care.

It was developed the technology of coating with the choice of powder granulation, spraying distance based on the obtained calculated data, confirmed experimentally. These data made it possible to obtain the necessary parameters of the coating strength and adhesion strength.

It is practically implemented the restoration of the peripheral part of the blade by gas-detonation method with further processing.

The recommendations for technological processes are provided based on the above parameters.

Testing of the repair technology of rectifiers was carried out on samples of rectifiers № 7 and 9 (Figure 6), on the laboratory device equipped with the vacuum chamber and the generator with a hollow cathode.

The samples were analyzed on a scanning microscope S-3700N. The microstructure of the sample taken from the soldered joint is shown in Figure 7 (image is reflected electrons). There is a fine-grained structure with a uniform distribution of grain sizes up to about 15-20 microns. There are no cracks or inconsistencies.

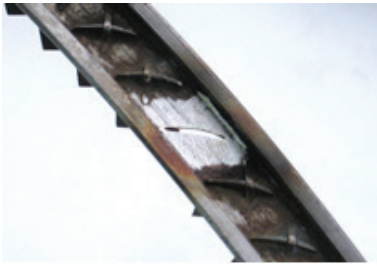

a.

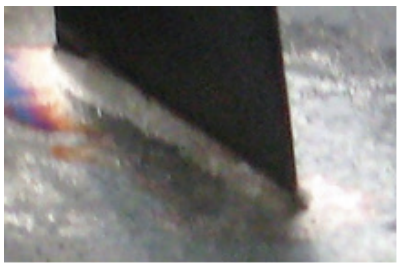

b.
Figure 6. Guide vanes repair: a - blade dismantling place after metalworking; $\mathrm{b}$ - a blade after soldering

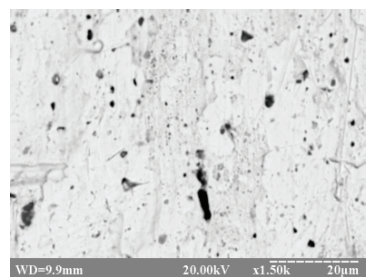

Figure 7. Microstructure and elemental composition of the solder joint sample
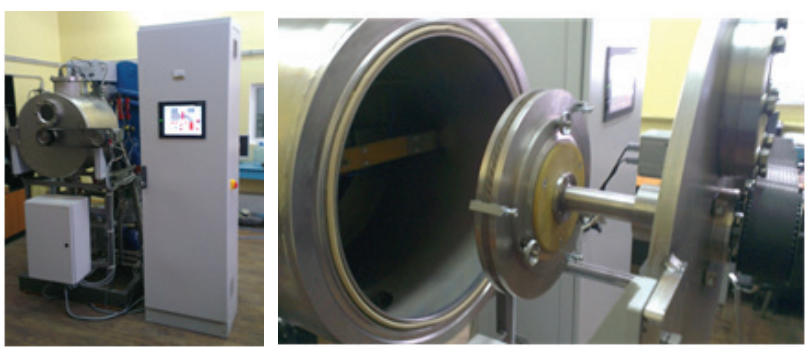

Preliminary studies suggest that the repair process of rectifiers by replacing the blades by soldering can be implemented at the industrial level. Thus, the full technical requirements for the industrial of vacuum soldering device (VSD) were formulated, developed (Figure 8), and implemented.

The obtained results allowed to develop the technological process of soldering and soldering of the blades of the half-rings of the rectifiers.

\section{Conclusions}

On the basis of mathematical modelling of the two-phase area in the barrel of the detonation unit in the flow out into the flooded space and interaction with the substrate, the parameters of velocity and temperature are calculated, rational regimes for $\mathrm{Al}_{2} \mathrm{O}_{3}$ materials are determined.

The recommendations for coating with the choice of powder granulation from 10 to $80 \mu \mathrm{m}$, spray distance from 100 to $150 \mathrm{~mm}$, which allows to obtain the necessary parameters of coating strength and adhesion Based on the obtained calculated data, confirmed experimentally.

The modernization of the detonation unit was carried out:

1) the vortex type batcher is developed and made that allows to dose powders of various granulation (from 10 to 80 microns) with a sampling error no more than $5 \%$;

2) it is developed the system of automated control of the detonation unit which according to the set program depending on the applied energy carriers and the put materials defines the cyclorama of work. This approach made it possible to provide technological parameters for the application of coatings with heating of the powder in a wide temperature range from 0.3 to 0.9 Tmelt, which is the most rational.

The soldering/unsoldering unit for compressor blades was developed with the use of special elements of devices that allow basing the blades of the rectifier in a semicircle both at the angle of installation and at the diameter of the sleeve. Technological recommendations on the purpose of technological modes of soldering and soldering with the use of PSR-50 are given.

On the basis of the performed calculations and experimental researches the complex technology of preparation of a surface for $\mathrm{Al}_{2} \mathrm{O}_{3}$ coatings deposition on blades made of titanium alloys, preparation of a surface before soldering and soldering technology is developed.

The results obtained in this research could be successfully applied for aircraft gasturbine engines' components restoration, ground power units, etc.

In the future, it is planned to study the potential for expanding the range of materials for renewable components, solders and coatings used in the aerospace industry. 


\section{References}

Alqallaf, J., Ali, N., Teixeira, J., Addali, A. (2020). Solid particle erosion behaviour and protective coatings for gas turbine compressor blades - A review. Processes, 8(8), 984. https://doi.org/10.3390/pr8080984

Anderson, J. D. (2012). Modern compressible flow. Tata McGrawhill India Pvt Ltd.

Boyce, M. P. (2012). Gas turbine engineering handbook (4th ed.). Elsevier Inc.

Ciafone, D. J. (Ed.). (2011). Gas turbines: Technology, efficiency and performance. Nova Science Publishers, Inc.

Davidson, P. (2015). Turbulence: An introduction for scientists and engineers. Oxford University Press. https://doi.org/10.1093/acprof:oso/9780198722588.001.0001

Dolmatov, A. I., \& Bilchuk, O. V. (2019). Simulation of process of solid particles sputtering with Dimet Nozzle. Metallofizika i Noveishie Tekhnologii, 41(7), 927-940. https://doi.org/10.15407/mfint.41.07.0927

Dolmatov, A. I., \& Bilchuk, O. V. (2018). Modelling of gas flow with solid particles in a Short Nozzle. Metallofizika $i$ Noveishie Tekhnologii, 40(9), 1257-1271. https://doi.org/10.15407/mfint.40.09.1257

Dolmatov, A. I., Sergeev, S. V., Kurin, M. O., Voronko, V. V., \& Loza, T. V. (2015). Kinematics of a solid particle accelerated by a gas flow in a supersonic nozzle and strain hardening of the treated surface. Metallofizika i Noveishie Tekhnologii, 37(7), 871 - 885. https://doi.org/10.15407/mfint.37.07.0871

Dolmatov, A. I., Danko, K. A., \& Neveshkin, Yu. O. (2014). Modeling the distribution of particles in a two-phase flow of a detonation-plasma unit. Metallofizika i Noveishie Tekhnologii, 11(36), 1533-1545. https://doi.org/10.15407/mfint.36.11.1533

Dolmatov, A. I., Kabatov, A. A., \& Kurin, M. A. (2013). Investigation and optimization of diamond smoothing technology as applied to stainless steel details for aircraft engines and aggregates. Metallofizika i Noveishie Tekhnologii, 10(35), 1407-1423.

Farokhi, S. (2014). Aircraft propulsion (2nd ed.). Wiley.

Grilli, M., Valerini, D., Slobozeanu, A., Postolnyi, B., Balos, S., Rizzo, A., \& Piticescu, R. (2021). Critical raw materials saving by protective coatings under extreme conditions: A review of last trends in alloys and coatings for aerospace engine applications. Materials, 14(7), 1656.

https://doi.org/10.3390/ma14071656
IDC Technologies. (2013). Gas turbines: Fundamentals, maintenance, inspection \& troubleshooting. IDC Technologies.

Jansohn, P. (Ed.). (2013). Modern gas turbine systems: High efficiency, low emission, fuel flexible power generation. Woodhead Publishing Limited, Alstom Technology Ltd. https://doi.org/10.1533/9780857096067

Karypis, G., \& Kumar, V. (1997). METIS - A software package for partitioning unstructured graphs, partitioning meshes, and computing fill-reducing orderings of Sparse Matrices. Version 3.0. Manual. University of Minnesota and Army HPC Research Center.

Kato, D., Pallot, G., Sugihara, A., \& Aotsuka, M. (2014). Research and development of a High Performance Axial Compressor. IHI Engineering Review, 47(1), 49-56.

Lomax, H., Pulliam, T. H., \& Zingg, D. W. (1999). Fundamentals of computational fluid dynamics. NASA Ames Research Center.

Menter, F. R. (1993, July). Zonal two-equation k- $\omega$ turbulence model for aerodynamic flows. In Paper presented at the AIAA 24th Fluid Dynamics Conference, AIAA-93-2906 (pp. 1-21). Orlando, Florida. https://doi.org/10.2514/6.1993-2906

Reitz, G., Dwinger, K., Schlange, S., Friedrichs, J., \& Kappei, F. (2016, April). Analysis of jet engine compressor deterioration and capturing correlations between geometric parameters. In 16th International Symposium on Transport Phenomena and Dynamics of Rotating Machinery (pp. 1-8). Honolulu, United States.

Sharma, S., Majila, A. N., Chavan, V. M., Fernando D. C., Patela, R. J., \& Babub, S. N. (2017). Effect of compressor blades' operational damages within an aircraft gas-turbine engine on its performance. Procedia Engineering, 173, 1894-1900. https://doi.org/10.1016/j.proeng.2016.12.247

Versteeg, H., \& Malalasekra, W. (2007). An Introduction to computational fluid dynamics: The finite volume method. Harlow Prentice Hall.

Volkov, K. (Ed.). (2012). Efficiency, performance and robustness of gas turbines. InTech.

White, F. M. (2011). Fluid mechanics. McGraw-Hill.

Wilcox, D. C. (2006). Turbulence modelling for CFD. DCW Industries.

Zorik, I. (2020). Numerical simulation of the outflow of two phase flow from detonation unit barrel. Technology Audit and Production Reserves, 2(1), 32-37. https://doi.org/10.15587/2706-5448.2020.201928 